\title{
RESUSCITATION AFTER CARDIAC SURGERY AWARENESS, AN EGYPTIAN MULTICENTRE SURVEY
}

\author{
Moslem Abdelghafar ${ }^{1}$, Taher Abdelmoiem² ${ }^{2}$ Alaa Mohamed ${ }^{3}$, and Mohamed Abdalla ${ }^{4}$ \\ ${ }^{1}$ Manchester University NHS Foundation Trust \\ ${ }^{2}$ National Heart Institute \\ ${ }^{3}$ Al-Azhar University \\ ${ }^{4}$ Shebin Elkom Teaching Hospital
}

April 16, 2021

\begin{abstract}
Aim: Cardiac surgery patients have different resuscitative needs than other patients who experience in-hospital cardiac arrest, this was addressed in the guidelines. However, it is unknown how widely the guidelines are practiced, or a training protocol is followed in different cardiac surgery units in Egypt. Methods: A 21-question survey is created and included: Participants demographics, Prevalence of cardiac arrest, Cardiac arrest protocol, Emergency resternotomy technique, Training protocols. Survey was disseminated through social media messaging platforms during the period between November 2020 and January 2021. Results: 95 responses were from 11 centres across Egypt. $68.5 \%$ of the respondents were surgeons, $76.8 \%$ of participants were junior surgeons. For patients who go into VF after cardiac surgery, respondents would attempt a median of 3 shocks with only $24.2 \%$ commencing defibrillation shocks before external cardiac massage, while the majority initiating CPR immediately and performing emergency resternotomy in a median time of 10 mins. 56.8\% would give $1 \mathrm{mg}$ of adrenaline as soon the cardiac arrest was established. If a surgeon was not available, only $36.8 \%$ of respondents would allow any trained personnel to perform the emergency resternotomy. Only $9.5 \%$ practice regularly on emergency sternotomies. $75 \%$ think tailored training is important and staff should be oriented about it in the future. Conclusion: An action plan is required to improve the awareness of the junior surgeons with the Cardiac Advanced Life Support Protocol.
\end{abstract}

\section{Hosted file}

Resuscitation after cardiac surgery awareness.pdf available at https://authorea.com/ users/408229/articles/518322-resuscitation-after-cardiac-surgery-awareness-an-egyptianmulticentre-survey 